\title{
ASSOCIATION BETWEEN ECG VARIABLES AND BODY MASS INDEX: A CROSS-SECTIONAL STUDY
}

\author{
K. N. Narasimha Swamy1, Amit Kumar², Sudhir G. K3 \\ 1 Professor and Head, Department of Physiology, Adichunchanagiri Institute of Medical Sciences, B. G. Nagara. \\ ${ }^{2}$ Final Year Post Graduate Resident, Department of Physiology, Adichunchanagiri Institute of Medical Sciences, B. G. Nagara. \\ 3Professor, Department of Physiology, Adichunchanagiri Institute of Medical Sciences, B G Nagara.
}

ABSTRACT
BACKGROUND
BMI is a surrogate marker for body fat, which does not directly estimate adiposity but affects ECG variables and can be used as
a novel measure in clinical practice to predict and assess cardiovascular morbidities.

\section{AIMS AND OBJECTIVES}

The study was done to correlate ECG variables like P-R interval, QRS duration and R-R interval with various ranges of BMI.

\section{MATERIALS AND METHODS}

Hundred healthy adult volunteers participated in this study. Their anthropometric data were recorded and BMI was calculated manually. Subsequently, the subjects were categorized into two BMI categories, those having BMI $<25$ (Category A) and those having BMI $\geq 25$ (Category B). Blood pressure and Lead II ECG variables like P-R interval, R-R interval and QRS duration were recorded.

\section{RESULTS}

The results showed that BMI of category B demonstrated statistically significant longer PR intervals and wider QRS durations. R-R interval though decreased with an increase in BMI, but was not statistically significant. ( $>0.05)$.

\section{CONCLUSION}

ECG variables like P-R interval and QRS duration were positively correlated with BMI. Longer P-R interval and wider QRS duration were observed with higher BMI category.

\section{KEYWORDS}

ECG variables, BMI, Body Fat, Obesity, P-R interval, QRS Duration.

HOW TO CITE THIS ARTICLE: K. N. Narasimha Swamy, Amit Kumar, Sudhir G. K. "Association between ECG Variables and Body Mass Index: A Cross-sectional Study." Journal of Evolution of Medical and Dental Sciences 2015; Vol. 4, Issue 96, November 30; Page: 16132-16135, DOI: 10.14260/jemds/2015/2364

\section{INTRODUCTION}

Obesity, a chronic non-communicable disease, as indicated by the World Health Organization (WHO), is one of the most rapidly growing public health problems worldwide. In 2010 overweight and obesity were estimated to cause 3.4 million deaths, $3.9 \%$ of years of life lost and $3.8 \%$ of Disability Adjusted Life-Years (DALY) worldwide.[1] India, a country where 270 million people live below the 'poverty line,' obesity seems to be a distant issue, but on the contrary India ranks as the third most obese country in the world lying just behind US and China in this global hazard list. [2] Worldwide obesity has doubled since 1980, as in 2014 more than 1.9 billion adults were overweight, of which over 600 million were obese.[3]

Financial or Other, Competing Interest: None.

Submission 11-11-2015, Peer Review 13-11-2015,

Acceptance 20-11-2015, Published 27-11-2015.

Corresponding Author:

Dr. Amit Kumar,

Final Year Post Graduate Resident,

Department of Physiology,

Adichunchanagiri Institute of Medical Sciences,

B. G. Nagara.

E-mail:amitkrsbg@gmail.com

DOI:10.14260/jemds/2015/2364
In India, the prevalence of overweight and obesity was recorded as high as $37.5 \%$ for females and $30.3 \%$ for males in North Indian state like Punjab. Obesity has reached epidemic proportions with more than $5 \%$ (As many as 5.2 crore) obese population and what is worse is, that it is expected to double in the next 5 years.[4] BMI if used with anthropometric measures can be used to predict adverse cardiovascular outcomes.[5]

According to WHO, "health is a state of complete physical, mental and social well-being and not merely the absence of disease or infirmity," whereas obesity is defined by WHO as "abnormal or excessive fat accumulation that presents a risk to health".[6] Obesity is associated with a wide variety of Electrocardiographic (ECG) abnormalities.

Most of these abnormalities reflect alterations in cardiac morphology or conduction defects. Some of the ECG parameters act as 'warning signals' for impending 'cardiac catastrophes' and as markers of risk for sudden death. The ECG abnormalities seen in obesity as compared to non-obese individuals include shift of $\mathrm{P}$-wave, lengthened wave durations, axis deviations and low voltage complexes.[7]

Thus, obesity is associated with a wide variety of ECG abnormalities, many of which are corrected by weight loss. BMI is considered as a simple and novel measure to estimate body fat percentage. Very few studies have been done in South-Asian population to study the correlation between ECG 
variables and BMI, hence this study was devised to find out the association between them.

\section{MATERIALS AND METHODS}

A cross-sectional study was performed at Post Graduate Research Laboratory, Department of Physiology, Adichunchanagiri Institute of Medical Sciences, B G Nagara, Mandya, Karnataka. Clearance was sought from Institutional Ethical Committee and all the volunteers were given a Performa before the start of the study. The volunteers were explained regarding the study and selected on the basis of the filled Performa.

A brief history was elicited and physical examination was performed. Subjects suffering from known cardiovascular, musculo-skeletal or metabolic diseases were excluded from the study. Only the subjects who gave written consent belonged to the desired age group and were not on any drugs affecting cardiovascular system were selected for the study. A total of 100 volunteers (58 males and 42 females) in the age group of 18-45years were selected for the study.

The subjects were advised about the risks and benefits of the procedure. During the study period, the subjects were instructed not to eat or drink caffeinated beverages 3 hours prior to testing. The following data of the subjects were recorded: Age, sex, height, weight and blood pressure.

Height was recorded using stadiometer with an adjustable ruler and weight was recorded using digital weighing scale of Diamond make, 2003 with a calibration of $0.1 \mathrm{~kg}$ as the minimum reading. Systolic and diastolic blood pressures were recorded using mercury sphygmomanometer of Lifeline Inc, New Delhi, 2010. BMI was calculated manually using Quetelet's index. The subjects were then categorized into two BMI categories - Category A - BMI $<25.0$ and Category B - BMI $\geq 25.0$.

\section{PROCEDURE FOR ECG RECORDING}

The subject was asked to lie in supine position on a table comfortably in a quiet room. After 5-minutes of rest in supine position, ECG (Lead II with speed of $25 \mathrm{~mm} / \mathrm{sec}$ ) was recorded for five minutes using a polygraph (RMS Polyrite version 1.0). ECG variables like P-R interval, $R-R$ interval and QRS duration were recorded.

\section{STATISTICAL ANALYSIS}

The data were expressed as Mean \pm Standard Deviation. A student's paired 't-test' was used for the dependent variables. An un-paired 't-test' was done for normally distributed variables. $P$ value $<0.05$ was considered statistically significant.

\section{RESULTS}

In this study a total of 100 subjects were evaluated. Out of that, 55 were males and 45 males. Further, out of the 45 males, 23 belonged to category A (BMI $<25)$ and the rest had BMI $\geq 25$. Similarly, out of the 55 females, 26 had BMI $<25$ and the rest 29 females had $\mathrm{BMI} \geq 25$. The anthropometric data and blood pressure for males of both categories are presented in Table 1 and that of females is presented in Table 2. Males had higher values of mean height and weight than the females. Category B had higher values of mean height, weight and systolic and diastolic blood pressure for both the sexes.

\section{MALES}

\begin{tabular}{|c|c|c|c|}
\hline $\begin{array}{c}\text { Parameters } \\
(\mathbf{n = ~ 4 5 )}\end{array}$ & $\begin{array}{c}\text { Category A } \\
(\mathbf{n = 3 4 )}\end{array}$ & $\begin{array}{c}\text { Category B } \\
(\mathbf{n = 1 1})\end{array}$ & P-value \\
\hline BMI & $20.51 \pm 3.85$ & $28.11 \pm 1.58$ & $0.0001^{* *}$ \\
\hline Height (in cm) & $159.76 \pm 7.93$ & $156.09 \pm 7.44$ & 0.1831 \\
\hline Weight (in kg) & $53.68 \pm 6.49$ & $68.64 \pm 6.93$ & $0.0001^{* *}$ \\
\hline $\begin{array}{c}\text { Systolic BP } \\
\text { (in mm of Hg) }\end{array}$ & $122 \pm 7.03$ & $122.91 \pm 7.12$ & 0.7117 \\
\hline $\begin{array}{c}\text { Diastolic BP } \\
\text { (in mm of Hg) }\end{array}$ & $79.06 \pm 7.99$ & $80.73 \pm 7.76$ & 0.5401 \\
\hline
\end{tabular}

Table1: BMI Based Grouping of Male Subjects

** - significant.

Category A - BMI $<25.0$, Category B - BMI $\geq 25.0$.

\section{FEMALES}

\begin{tabular}{|c|c|c|c|}
\hline $\begin{array}{c}\text { Parameters } \\
(\mathbf{n = 5 5})\end{array}$ & $\begin{array}{c}\text { Category A } \\
(\mathbf{n = 4 3})\end{array}$ & $\begin{array}{c}\text { Category B } \\
(\mathbf{n = 1 2})\end{array}$ & p-value \\
\hline BMI & $20.14 \pm 2.79$ & $27.3 \pm 2.87$ & $0.0001^{* *}$ \\
\hline Height (In cm) & $155.67 \pm 5.48$ & $155.25 \pm 3.89$ & 0.8052 \\
\hline Weight (In kg) & $49.05 \pm 7.58$ & $64.92 \pm 6.75$ & $0.0001^{* *}$ \\
\hline $\begin{array}{c}\text { Systolic BP } \\
\text { (In mm of Hg) }\end{array}$ & $119.07 \pm 5.59$ & $126.5 \pm 6.99$ & $0.0003^{* *}$ \\
\hline $\begin{array}{c}\text { Diastolic BP } \\
\text { (In mm of Hg) }\end{array}$ & $76.33 \pm 7.77$ & $83 \pm 6.69$ & $0.0092^{* *}$ \\
\hline
\end{tabular}

Table-2: BMI Based Grouping of Female Subjects

** - significant.

Category A - BMI $<25.0$, Category B - BMI $\geq 25.0$.

Table 3 shows the ECG variables in both sexes with relation to both the categories. In the higher BMI category, there is a statistically significant increase in P-R interval as well as QRS duration in both the sexes. There was an increase in R-R interval as well but it was not statistically significant. Figure 1 is the graphical representation of variation in P-R interval with respect to BMI in both the sexes. Figure 2 is the graphical representation of variation in QRS duration with respect to BMI in both the sexes.

Student's unpaired 't-test' was applied to get the $p$-value and $p<0.05$ was considered as significant.

\begin{tabular}{|c|c|c|c|c|c|c|}
\hline & \multicolumn{3}{|c|}{ Males (n = 45) } & \multicolumn{3}{c|}{ Females (n = 55) } \\
\hline & $\begin{array}{c}\text { Category } \\
\text { A (n = 34) }\end{array}$ & $\begin{array}{c}\text { Category } \\
\text { B (n = 11) }\end{array}$ & $\mathbf{P}$ - value & $\begin{array}{c}\text { Category } \\
\text { A (n = 43) }\end{array}$ & $\begin{array}{c}\text { Category } \\
\text { B (n = 12) }\end{array}$ & P - value \\
\hline P-R interval & $141.7 \pm 16.2$ & $197.3 \pm 8.6$ & $0.0001^{* *}$ & $148.2 \pm 20.83$ & $192 \pm 14.87$ & $0.0001^{* *}$ \\
\hline QRS Duration & $77.6 \pm 13.2$ & $106.2 \pm 8.1$ & $0.0001^{* *}$ & $76.7 \pm 12.3$ & $116.5 \pm 7.68$ & $0.0001^{* *}$ \\
\hline R-R interval & $820.4 \pm 65.9$ & $757.6 \pm 49.6$ & 0.721 & $831.7 \pm 73.6$ & $728.6 \pm 64.5$ & 0.4191 \\
\hline \multicolumn{3}{|c|}{ Table 3: ECG Variables of Males and Females Varying BMI } \\
\hline
\end{tabular}

** - significant 


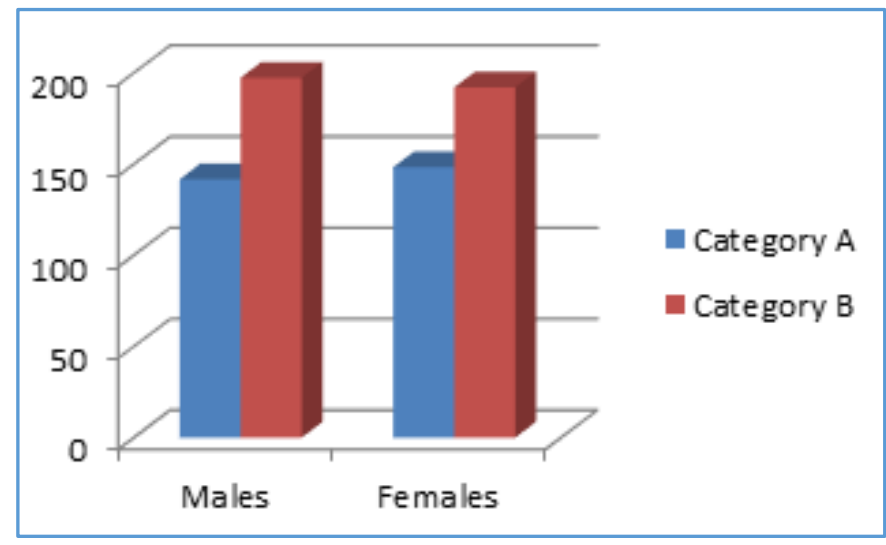

Fig. 1: Variation of P-R Interval with BMI

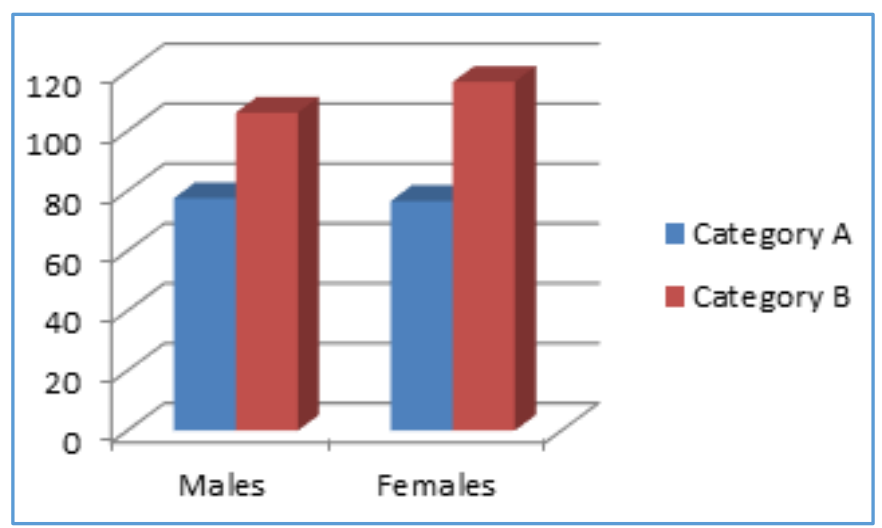

Fig. 2: Variation of QRS Duration with BMI

Figure 3 and 4 are linear regression curves of BMI (x-axis) with respect to P-R interval (y-axis) in males and females respectively. Figure 5 and 6 respectively are linear regression curves of BMI (x-axis) with respect to QRS Duration (y-axis) in males and females respectively.

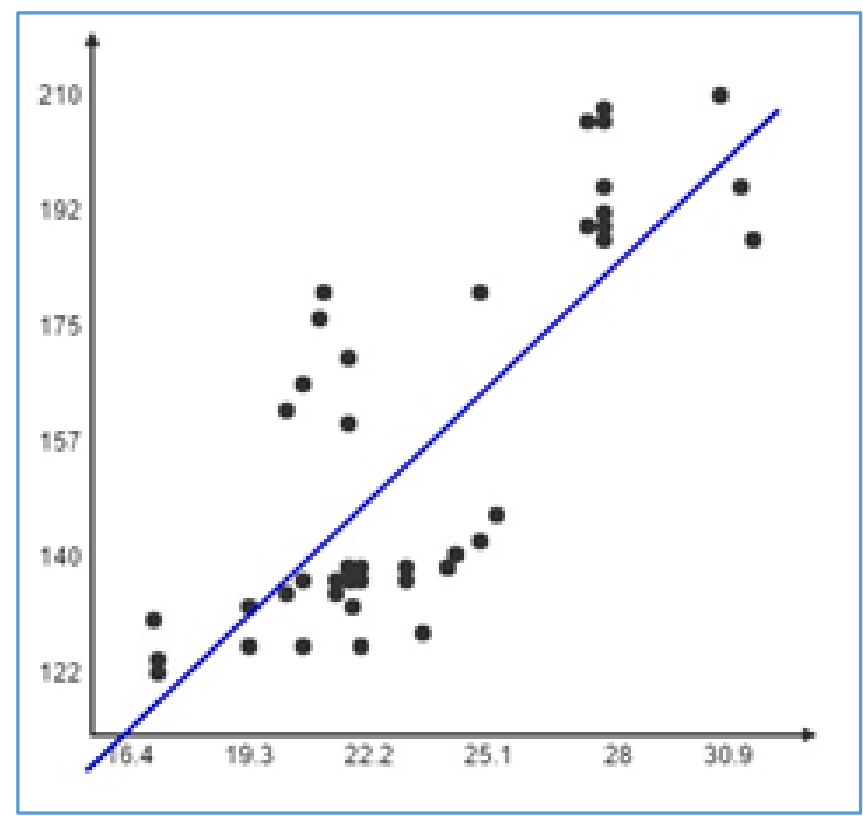

Fig. 3: Showing Correlation of BMI (X-axis) with that of P-R Interval in Milliseconds (Y-axis) in Males. $(R=+0.7796)$

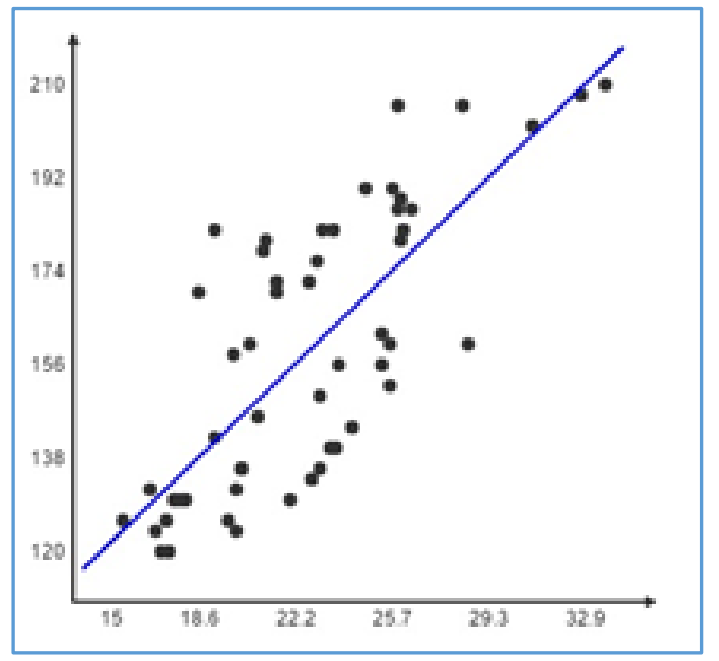

Fig. 4: Showing Correlation of BMI (X-axis) with that of P-R Interval in Milliseconds ( $Y$-axis) in Females. $(R=+0.7652)$

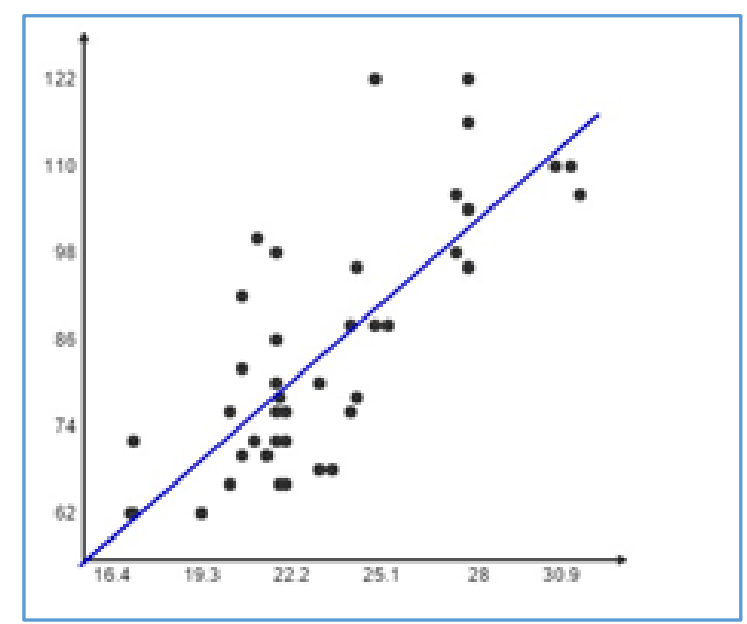

Fig. 5: Showing Correlation of BMI (X-axis) with that of QRS Interval in Milliseconds (Y-axis) in Males.

$$
\text { ( } R=+0.7885)
$$

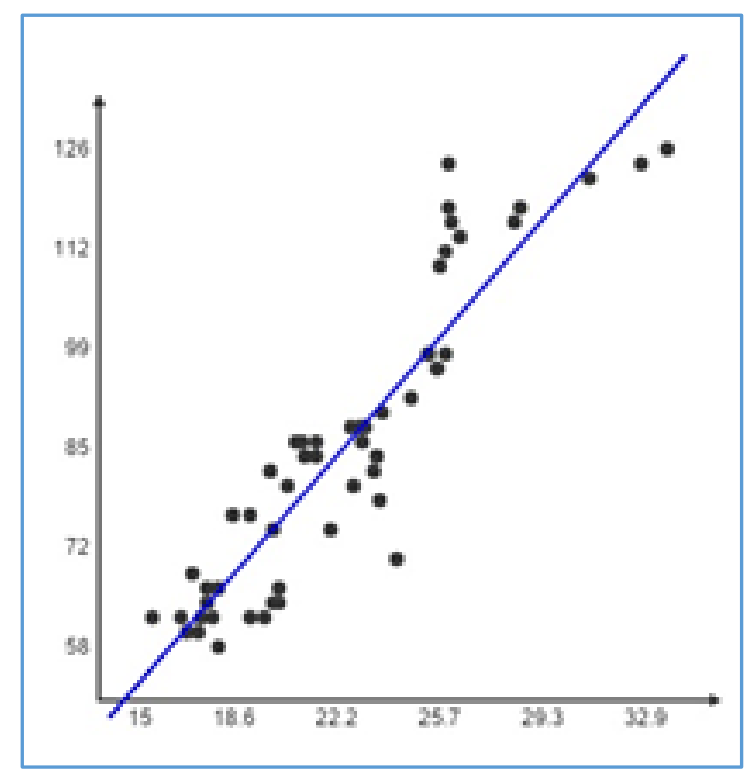

Fig. 6: Showing Correlation of BMI (X-axis) with that of QRS Duration in Milliseconds (Y-axis) in Females.

$(R=+0.9157)$ 


\begin{tabular}{|c|c|c|c|}
\hline Parameters & $\begin{array}{c}\text { P-R } \\
\text { Interval }\end{array}$ & $\begin{array}{c}\text { QRS } \\
\text { Duration }\end{array}$ & $\begin{array}{c}\text { R-R } \\
\text { Interval }\end{array}$ \\
\hline Males & $+0.7796^{* *}$ & $+0.7885^{* *}$ & $-0.3836^{*}$ \\
\hline Females & $+0.7652^{* *}$ & $+0.9157^{* * *}$ & $-0.5632^{*}$ \\
\hline $\begin{array}{c}\text { Table 4: Depicting the Correlation Coefficients (R-values) } \\
\text { of BMI and various ECG Parameters in Both the Sexes }\end{array}$ \\
\hline
\end{tabular}

* - weak correlation, ${ }^{* *}$ - strong correlation, ${ }^{* * *}$ - very strong correlation.

\section{DISCUSSION}

BMI, since decades, has been the most used parameter to study effect of obesity on various organ systems because of its feasibility and easy of interpretation. ECG is a simple and noninvasive procedure, in which the electrical activities of heart can be recorded by placing electrodes on the skin of the chest and connected them in a specific order to electrocardiograph that records the activities. But there have been paucity of researches correlating BMI with ECG parameters.

BMI, although the most commonly used variable to classify individuals as overweight or obesity is just a proxy tool to estimate body fat. It does not take variables like lean body mass, ethnicity, sex and age into consideration. Further, it does not give an idea of the distribution of body fat. But BMI correlates reasonably well with body fat. An increase in body fat significantly alters the autonomic functioning of an individual, cardiovascular functions being one of them. An obese individual has altered cardiovascular parameters which get reflected in various ECG variables. ${ }^{[8]}$

TW Shen and WJ Thompkin, in their study on ECG and BMI stated that ECG can be used as a potential biometric for human identity verification. Their results showed that ECG features of male better correlate with BMI model than that of females.[9] In our study, we found that ECG variables like P-R interval and QRS duration were linearly correlated with body mass index and it was statistically significant.

However, no significant association was found between BMI and R-R interval $(\mathrm{P}>0.05)$. The results of the current study indicate that increase in BMI was associated with longer P-R interval and wider QRS duration. The reason for the same is obscure, but may be due to the fact that obesity causes an increase in blood volume.[10] leading to concentric hypertrophy of the cardiac musculature leading to conduction defects and thus increase in P-R interval.

R S Vasan in his study on cardiac function and obesity (2003) stated that obesity is associated with haemodynamic overload and the increased metabolic demand imposed by the expanded adipose tissue in obesity results in a hyperdynamic circulation with increased blood volume.[11]

In addition to that, electrodermal activity has a negative association with obesity as seen in the study conducted Park AE et al.[12] Skin resistance delays the conductance of the impulses from the site of generation to the surface of the skin leading to increase in P-R interval and/or widening of the QRS complex. Further researches with purview to our study could enlighten us more about the association of BMI and ECG variables in near future.

\section{CONCLUSION}

Thus the present work concluded that ECG variables like P-R interval and QRS duration increase with an increase in BMI. The drawback of this study was that the age group selected for the study could have been wider. Also, we could not study the effects of increasing age on ECG variables. There is a scope for further studies to be done taking the parameters of age and sex on ECG variables.

\section{REFERENCES}

1. Ng M, Fleming T, Robinson $\mathrm{M}$, Thomson B, Graetz N, Margono C, et al. Global, regional and national prevalence of overweight and obesity in children and adults during 1980-2013: a systematic analysis for the Global Burden of Disease Study 2013. Lancet 2014;384(9945):766-81.

2. Neetu CS. India the third most obese country in the world. India Today, New Delhi, 2014.

3. http://www.who.int/mediacentre/factsheets/fs311/en /index.html [Accessed on 10.10.2015].

4. Kalra S, Unnikrishnan A G. Obesity in India: The weight of the nation. J Med Nutr Nutraceut. 2012;1:37-41.

5. Ryan TH, Christopher K, Laura AB, Stephen AM. The obesity epidemic: Challenges, health initiatives, and implications for gastroenterologists. Gastroenterol Hepatol. 2010;6(12):780-92.

6. http://www.who.int/about/definition/en/print.html [accessed on 16.07.2015].

7. Fraley MA, Birchem JA, Senkottaiyan N, Alpert MA. Obesity and the electrocardiogram. Obes Rev 2005;6(4):275-81.

8. Valensi $\mathrm{P}$ et al. Cardiac Autonomic Functions in obese patients. Int J Obes Relatd Metab Disord. 2005;19(2):113-8.

9. Shen TW, Tompkins WJ. Biometric statistical study of one-lead ECG features and Body Mass Index (BMI). Proceedings of the 2005 IEEE. Engineering in Medicine and Biology 27th Annual Conference. Shanghai, China, September 1-4, 2005.

10. Kim G, Kathy L, Beth AC. The effects of Obesity on the cardiopulmonary system: Implications for Critical Care Nursing. Prog Cardiovasc Nurs. 2004;19(4):6-13.

11. Vasan RS. Cardiac function and obesity. Heart. 2003;89(10):1127-9.

12. Park AE, Huynh P, Schell AM, Baker LA. Relationship between obesity, negative affect and basal heart rate in predicting heart rate reactivity to psychological stress among adolescents. 2015;97(2):139-44. 